Supporting Information

\title{
Ambient-Temperature Hydrogen Storage via Vanadium(II)-Dihydrogen Complexation in a Metal-Organic Framework
}

\author{
David E. Jaramillo ${ }^{1,2}$, Henry Z. H. Jiang ${ }^{1,2}$, Hayden A. Evans ${ }^{3}$, Romit \\ Chakraborty $^{1,4}$, Hiroyasu Furukawa ${ }^{1,2}$, Craig M. Brown ${ }^{3,5}$, Martin Head-Gordon ${ }^{1,4}$, \\ and Jeffrey R. Long ${ }^{1,2,6^{*}}$ \\ ${ }^{1}$ Department of Chemistry, University of California, Berkeley, California 94720, United States. \\ ${ }^{2}$ Materials Sciences Division, Lawrence Berkeley National Laboratory, Berkeley, California \\ 94720, United States. \\ ${ }^{3}$ Center for Neutron Research, National Institute of Standards and Technology, Gaithersburg, \\ Maryland 20899, United States \\ ${ }^{4}$ Chemical Sciences Division, Lawrence Berkeley National Laboratory, Berkeley, CA 94720 \\ United States. \\ ${ }^{5}$ Chemical and Biomolecular Engineering, University of Delaware, Newark, Delaware 19716, \\ United States \\ ${ }^{6}$ Department of Chemical and Biomolecular Engineering, University of California, Berkeley, \\ California 94720, United States. \\ *Correspondence to: jrlong@berkeley.edu
}




\section{Table of contents}

\section{Materials and methods}

Figure S1. $\mathrm{N}_{2} 77 \mathrm{~K}$ isotherm and BET plot

Figure S2. Entropy of $\mathrm{H}_{2}$ adsorption as a function of loading

Figure S3. $120 \mathrm{~K}$ infrared spectrum of $\mathrm{H}_{2}$-dosed $\mathrm{V}_{2} \mathrm{Cl}_{2.8}$ (btdd)

Figure S4. Rietveld refinement of activated $\mathrm{V}_{2} \mathrm{Cl}_{2.8}$ (btdd) X-ray diffraction data

Figure S5. Rietveld refinement of $\mathrm{D}_{2}$-dosed $\mathrm{V}_{2} \mathrm{Cl}_{2.8}$ (btdd) X-ray diffraction data

Figure S6. Rietveld refinement of activated $\mathrm{V}_{2} \mathrm{Cl}_{2.8}$ (btdd) neutron diffraction data

Figure S7. Rietveld refinement of $\mathrm{D}_{2}$-dosed $\mathrm{V}_{2} \mathrm{Cl}_{2.8}(\mathrm{btdd})$ neutron diffraction data

Figure S8. $R_{w p}$ versus D superatom position

Figure S9. High-pressure total uptake hydrogen isotherms

Figure S10. High-pressure excess uptake hydrogen isotherms

Figure S11. Calculated surface coverage of vanadium sites

Figure S12. Calculated isotherms from Langmuir-Freundlich high-pressure fits

Figure S13. EDA results across different functionals

Figure S14. Depiction of orbital pairs involved in charge transfer interaction

Table S1. BET plot parameters of $77 \mathrm{~K} \mathrm{~N}_{2}$ isotherm

Table S2. Tri-site Langmuir-Freundlich fit parameters for low-pressure data

Table S3. Dual-site Langmuir-Freundlich fit parameters for high-pressure data

Table S4. Calculated free energies and enthalpies of $\mathrm{H}_{2}$ binding in cluster model

Table S5. EDA results for cluster model

\section{References}




\section{Materials and methods}

General considerations. All synthetic procedures were performed under an argon atmosphere using standard Schlenk techniques or in an $\mathrm{N}_{2}$-filled VAC Atmospheres glove box..$^{\S}$ Methanol was purchased from EMD Millipore Corporation as DriSolv grade, dried over $3 \AA$ molecular sieves, and sparged with argon before use. $N, N$-dimethylformamide (DMF) was purchased from EMD Millipore Corporation as OmniSolv grade, sparged with argon, and dried with an alumina column before use.

Synthesis of $\mathbf{V}_{\mathbf{2}} \mathbf{C l}_{\mathbf{2} .8}$ (btdd). $\mathrm{V}_{2} \mathrm{Cl}_{2.8}$ (btdd) was synthesized as previously described. ${ }^{1}$ For convenience, the synthesis details are included here. A DMF solution $(10 \mathrm{ml})$ containing $\mathrm{VCl}_{2}(\text { tmeda })_{2}(90.0 \mathrm{mg}, 0.254 \mathrm{mmol})$ and dimethylformamidium trifluoromethanesulfonate (266 $\mathrm{mg}, 1.20 \mathrm{mmol}$ ) was added to a $20-\mathrm{ml}$ borosilicate vial containing $\mathrm{H}_{2}$ (btdd) $(20.0 \mathrm{mg}, 0.0752$ mmol). The reaction mixture was placed on a hot plate at $120^{\circ} \mathrm{C}$, without stirring, for 7 days. The resulting dark purple powder was filtered and soaked in $10 \mathrm{ml}$ of DMF at $120^{\circ} \mathrm{C}$ for $24 \mathrm{~h}$. The supernatant solution was removed, another $10 \mathrm{ml}$ of DMF was added and the vial was heated at $120{ }^{\circ} \mathrm{C}$ for $24 \mathrm{~h}$. This process was repeated five more times. The resulting solid was collected by filtration, and soaked in $10 \mathrm{ml}$ of methanol at $60{ }^{\circ} \mathrm{C}$ for $12 \mathrm{~h}$. The supernatant solution was decanted, and the remaining powder was soaked in another $10 \mathrm{ml}$ of methanol at $60{ }^{\circ} \mathrm{C}$ for $12 \mathrm{~h}$. This process was repeated four more times. The resulting solid was collected by filtration, and heated at a rate of $0.2{ }^{\circ} \mathrm{C} \mathrm{min}$ m $^{-1}$ and held at $180{ }^{\circ} \mathrm{C}$ under dynamic vacuum for $36 \mathrm{~h}$, affording 20 $\mathrm{mg}$ of product as a dark purple powder.

Low-pressure hydrogen adsorption measurements. Hydrogen adsorption isotherms were collected between 0 and 1 bar using a volumetric method with a Micromeritics ASAP2020 or Micromeritics 3Flex gas sorption analyzer. In an $\mathrm{N}_{2}$ filled glovebox, a typical sample of approximately $50 \mathrm{mg}$ was transferred to a pre-weighed analysis tube, which was capped with a Micromeretics TranSeal and evacuated by heating at $180^{\circ} \mathrm{C}$ with a ramp rate of $0.2^{\circ} \mathrm{C} / \mathrm{min}$ under dynamic vacuum until an outgas rate of less than $3 \mu \mathrm{bar} / \mathrm{min}$ was achieved. The evacuated analysis tube containing the degassed sample was then carefully transferred to an electronic balance and weighed again to determine the mass of sample. The tube was then transferred back to the analysis port of the gas adsorption instrument. The outgas rate was again confirmed to be less than 3 $\mu \mathrm{bar} / \mathrm{min}$. For all isotherms, warm and cold free space correction measurements were performed using ultra-high purity $\mathrm{He}$ gas (UHP grade 5.0, 99.999\% purity); $\mathrm{H}_{2}$ isotherms at 273 to $298 \mathrm{~K}$ were measured in water baths equipped with a Julabo F32 circulator. Oil-free vacuum pumps and oil-free pressure regulators were used for all measurements to prevent contamination of the samples during the evacuation process or of the feed gases during the isotherm measurements.

Adsorption isotherm fitting. Low-pressure isotherms were fit with a tri-site LangmuirFreundlich equation (eq. 1, see Table S2), where $n$ is the total amount adsorbed in $\mathrm{mmol} / \mathrm{g}, P$ is the pressure in bar, $n_{s a t, i}$ is the saturation capacity in $\mathrm{mmol} / \mathrm{g}, b_{i}$ is the Langmuir parameter in bar $^{-1}$ defined in eq. 2 , and $v_{i}$ is the Freundlich parameter for each site.

$$
n=\frac{n_{s a t, 1} b_{1} P^{v_{1}}}{1+b_{1} P^{v_{1}}}+\frac{n_{s a t, 2} b_{2} P^{v_{2}}}{1+b_{2} P^{v_{2}}}+\frac{n_{s a t, 3} b_{3} P^{v_{3}}}{1+b_{3} P^{v_{3}}}
$$

\footnotetext{
$\S$ Certain commercial equipment, instruments, or materials are identified in this document. Such identification does not imply recommendation or endorsement by the National Institute of Standards and Technology, nor does it imply that the products identified are necessarily the best available for the purpose.
} 


$$
b_{i}=e^{S_{i} / R} e^{\frac{-E_{i} \cdot 1000}{R T}}
$$

For eq. $2, S_{i}$ is the site-specific entropy of adsorption in units of $\mathrm{J} /(\mathrm{mol} \cdot \mathrm{K}), E_{i}$ is the enthalpy of adsorption in units of $\mathrm{kJ} / \mathrm{mol}, R$ is the ideal gas constant in units of $\mathrm{J} /(\mathrm{mol} \cdot \mathrm{K})$, and $T$ is the temperature. Isotherms collected at high pressures were fit with a dual-site Langmuir-Freundlich equation, using only the first two terms in eq. 1 (see Table S3).

Differential enthalpies and entropies of adsorption. Using the tri-site Langmuir-Freundlich fits, the differential enthalpies of adsorption, $\Delta H$, and entropies of adsorption, $\Delta S$, were calculated using the Clausius-Clapeyron relationship (eq. 3), where $R$ is the ideal gas constant, $P$ is the pressure, and $T$ is the temperature.

$$
\ln P=-\frac{\Delta H}{R}\left(\frac{1}{T}\right)+\frac{\Delta S}{T}
$$

In particular, the pressure corresponding to exact loadings across three different temperatures was calculated. From the linear relation (eq. 3), the slope provides the enthalpy of adsorption and the $y$-intercept provides the entropy of adsorption at that given loading.

Infrared spectroscopy. Infrared spectra were collected using a Bruker Vertex 70 spectrometer equipped with a glowbar source, $\mathrm{KBr}$ beamsplitter, and a liquid nitrogen cooled mercurycadmium-telluride detector. A custom-built diffuse reflectance system with an IR-accessible gas dosing cell was used for all measurements. Sample temperature was controlled by an Oxford Instruments OptistatDry TLEX cryostat, and sample atmosphere was controlled by a Micromeritics ASAP 2020Plus gas sorption analyzer. Prior to measurement, activated $\mathrm{V}_{2} \mathrm{Cl}_{2.8}$ (btdd) (10 wt\%) was dispersed in dry $\mathrm{KBr}$ in an argon-filled glovebox and evacuated at room temperature for 30 minutes. Spectra were collected in situ under UHP-grade $\mathrm{H}_{2}$ and $\mathrm{D}_{2}$ at 4 $\mathrm{cm}^{-1}$ resolution continually until equilibrium was observed.

High-pressure hydrogen isotherms. Data were collected using a previously published procedure ${ }^{2}$ with slight modifications. Activated $\mathrm{V}_{2} \mathrm{Cl}_{2.8}$ (btdd) $(\sim 340 \mathrm{mg})$ was transferred into a custom-made high-pressure sample holder with an isolation valve in an $\mathrm{N}_{2}$ filled glovebox. A stainless-steel dowel was placed in the holder to minimize the dead space. High-pressure isotherms were measured on an HPVA II-200 from the Particulate Systems using $\mathrm{H}_{2}$ pressures ranging from $\sim 1$ bar to 150 bar. Ultra-high purity grade $\mathrm{H}_{2}$ and $\mathrm{He}(99.999 \%)$ gases were used throughout the adsorption experiments. When the manifold was pressurized above 100 bar, an air-driven gas booster (DLE 75-1-G-H2, Maximator) was used. The sample holder temperature was controlled using a bath circulator (Julabo FP89-HL/TK) filled with silicone heat transfer fluid (Syltherm XLT, Dow). Isotherms were collected by dosing $\mathrm{H}_{2}$ to the sample in a step-wise fashion, and each data point was taken after sufficient time for equilibration. Ideally, the adsorption of $\mathrm{H}_{2}$ isotherm for an empty sample holder should be zero; however, this is not often true. In this work, $\mathrm{H}_{2}$ isotherms for the sample holder containing non-porous copper wire were recorded at each temperature and subtracted from the isotherm to perform a baseline correction. The volume of the wire in the holder was determined by the skeletal volume of $\mathrm{V}_{2} \mathrm{Cl}_{2.8}(\mathrm{btdd})$, estimated by the average of ten He expansion measurements. 
The total $\mathrm{H}_{2}$ uptake was estimated using a simple equation since it is not possible to determine directly: $($ total uptake $)=($ excess uptake $)+\left(\right.$ bulk $\mathrm{H}_{2}$ density $) \times($ pore volume $)$. A dual Langmuir Freundlich model was used to fit total adsorption isotherms with temperature-independent parameters, allowing estimation of the $\mathrm{H}_{2}$ uptake up to 250 bar (Figure S10). For the estimation of volumetric adsorption capacity, the calculated crystal density of $\mathrm{V}_{2} \mathrm{Cl}_{2.8}(\mathrm{btdd})\left(0.641 \mathrm{~g} / \mathrm{cm}^{3}\right)$ was employed. A pore volume $\left(1.12 \mathrm{~cm}^{3} / \mathrm{g}\right)$ was estimated from a $77 \mathrm{~K} \mathrm{~N}_{2}$ isotherm using the DubininRadushkevich method.

Powder X-ray diffraction data collections. High-resolution synchrotron X-ray powder diffraction data was collected at Beamline 17-BM at the Advanced Photon Source at Argonne National Laboratory. The temperature of the capillary sample was achieved using an Oxford Cryosystems Cryostream 800 . Scattered intensity was measured by a PerkinElmer amorphous-Si flat panel detector. The wavelength for the measurements was $0.45236 \AA$. Microcrystalline powder samples of $\mathrm{V}_{2} \mathrm{Cl}_{2.8}$ (btdd) $(\approx 5 \mathrm{mg})$ were loaded into $1.0 \mathrm{~mm}$ boron-rich glass capillaries inside a $\mathrm{N}_{2}$ glovebox. The capillaries were attached to custom valve-based dosing sample holders and reactivated under dynamic vacuum at $180^{\circ} \mathrm{C}$ at the beamline. After diffraction data were collected for the activated material at $100 \mathrm{~K}$, the sample was connected to a fixed-volume gas manifold, dosed with 0.75 equiv. of $\mathrm{D}_{2}$ at room temperature, and cooled to $100 \mathrm{~K}$ for data collection. Residual pressure remained in the line at $100 \mathrm{~K}$.

Powder neutron diffraction data collections. Data were collected at the National Institute of Standards and Technology Center for Neutron Research (NCNR) on a $0.44 \mathrm{~g}$ sample of $\mathrm{V}_{2} \mathrm{Cl}_{2.8}$ (btdd), using the high-resolution neutron powder diffractometer BT-1, which features a $\mathrm{Ge}(311)$ monochromator with an in-pile 60' collimator, corresponding to a neutron wavelength of $2.0775 \AA$. The activated sample was loaded into a vanadium sample can in a He glovebox and sealed with an indium o-ring onto a copper heating block containing a valved outlet for gas loading. After mounting the sample onto a bottom-loaded closed cycle refrigerator, the sample was put under vacuum for enough time to sufficiently remove He, then cooled to $100 \mathrm{~K}$ for data collection. For $\mathrm{D}_{2}$ gas dosing, the sample was connected to a fixed-volume gas manifold, heated to $200 \mathrm{~K}$, dosed with approximately 0.75 equivalents of $\mathrm{D}_{2}$ per vanadium(II) site, and cooled to $100 \mathrm{~K}$ for data collection.

Powder X-ray diffraction data analysis. Activated $\mathrm{V}_{2} \mathrm{Cl}_{2.8}(\mathrm{btdd})$ was measured at $100 \mathrm{~K}$ for sufficient time to be able to perform high quality Rietveld refinements (Figure S3). Space group $R \overline{3} m$ was chosen based on the previously reported structure obtained from X-ray diffraction. ${ }^{1}$ For $\mathrm{X}$-ray analysis of the activated and $\mathrm{D}_{2}$ dosed material (dosed with 0.75 equivalents of $\mathrm{D}_{2}$ per vanadium(II) center), unit cell parameters and vanadium and chlorine positions were refined (Figure S4). These values were used as constants for neutron data refinements. Due to low intensity of high $Q$ data, chemically reasonable thermal parameter values were assigned. $\mathrm{V}$ atoms were modeled with full occupancy. The bridging $\mathrm{Cl}$ was modeled with full occupancy, and the apical $\mathrm{Cl}$ was modeled with 0.4 occupancy, as in previous work. ${ }^{1}$

Powder neutron diffraction data analysis. Data for the activated material were collected at $100 \mathrm{~K}$ for sufficient time to be able to perform high quality Rietveld refinements (Figure S5). Powder neutron diffraction data were analyzed using the TOPAS software suite. Initial Pawley refinements were conducted to determine lattice parameters and peak shapes. ${ }^{3}$ The peak shape of the activated model was applied to the subsequent dosing refinement for consistency. Unit cell parameters, $\mathrm{V}$ and $\mathrm{Cl}$ positions, thermal parameters, and occupancies of the $\mathrm{V}$ and $\mathrm{Cl}$ atoms were 
fixed at values obtained from X-ray analysis. The position and orientation of the btdd ${ }^{2-}$ ligands were refined using soft restraints, and were found to deviate from expected planarity, indicative of ligand disorder. For analysis of data obtained upon $\mathrm{D}_{2}$ dosing, the 'superatom' approach was used to approximate the $\mathrm{D}_{2}$ molecule as a single D-atom (Figures S6 and S7). ${ }^{4-6}$ Stoichiometric gas dosing measurements were done with approximately $0.75 \mathrm{D}_{2}$ to $\mathrm{V}(\mathrm{II})$. The data sets were recorded at $100 \mathrm{~K}$ to complement $\mathrm{X}$-ray analysis. As $\mathrm{V}$ is essentially neutron transparent, and the btdd ${ }^{2-}$ linkers do not contribute as much to the overall scattering in X-ray analysis, similar experimental conditions between neutron and X-rays data acquisition (and identical samples) were needed for direct comparison but cannot be guaranteed to be identical enough for a combined X-ray/neutron refinement for both data sets simultaneously.

Structural model verification. During the refinements of both X-ray and neutron data, certain peaks were found to under and over fit. We examined the possibility that the structure was better described with a quadrupled unit cell ( $a=b=77.8 \AA, c=8.83 \AA$ ). From this supercell, the suspect peaks were identified to be of the $(3 h 00)$ family. The $(3 h 00)$ planes contain primarily the btdd ${ }^{2-}$ linkers, but also the bridging and apical chlordies. The peak issues of the (3h00) family was present in the X-ray data, but more pronounced in the neutron data as this technique is more sensitive to the scattering of the btdd ${ }^{2-}$ linkers. A lower symmetry space group, $R \overline{3}$ (\#148), was implemented [which has an identical $h k l$ pattern as $R \overline{3} m$ (\#166)] so as to easily model two independent btdd ${ }^{2-}$ linkers with rigid bodies. Combined with the refinement of the $\mathrm{Cl}$ positions, the fit of this family of peaks were slightly improved in both X-ray and neutron data. However, though the fitting of these peaks could be slightly improved with the proposed supercell, the overall fit with this lower symmetry model compared to the fit using the higher symmetry, $R \overline{3} m$, model was not statistically better. For this reason, the high symmetry $R \overline{3} m$ model was chosen to continue refinements with. There is potential though that a distortion similar to that which has previously been reported for xylene exposed $\mathrm{Co}_{2}$ (dobdc) may occur. ${ }^{7}$

To account for the suspected distortion, the btdd ${ }^{2-}$ linker was refined with soft restraints using the neutron data. The refined btdd ${ }^{2-}$ ligand is somewhat distorted as a result and is utilized for all refinement models reported. Furthermore, as the $\mathrm{V}_{2} \mathrm{Cl}_{2.8}(\mathrm{btdd})$ is difficult to prepare and sample variation is possible, the deviation from planarity of the btdd ligand may just be indicative of a bulk-average of sample variation (as the sample size for neutron diffraction is much larger than the X-ray sample). This potential sample variation and variability in exact dosing conditions (for synchrotron, residual pressure of 3 torr $\mathrm{D}_{2}$ on a $0.7 \mathrm{mg}$ sample, for neutron, residual pressure of 73 torr $\mathrm{D}_{2}$ on $440 \mathrm{mg}$ sample), are reasons why neutron and X-ray data were treated separately as opposed to using both sets simultaneously for a joint refinement.

$\mathbf{D}_{2}$ occupancy and location. Initial testing of possible $\mathrm{D}_{2}$ locations was informed via Fourier difference maps of neutron diffraction data, and chemical reasoning based on similar transition metal systems. The $\mathrm{D}_{2}$ was modeled as a $\mathrm{D}$ superatom as it is a quantum object. ${ }^{4,6}$ Due to apparent disorder in $\mathrm{V}_{2} \mathrm{Cl}_{2.8}$ (btdd), as well as density near $2.3 \AA$ from the partial occupancy of the apical $\mathrm{Cl}$, we examined the effect of moving $\mathrm{D}_{2}$ along the special position of $x, 0,0.5$ on refinement statistics (Figure S7) in order to gauge a possible range of interaction distances. The likely range of $\mathrm{D}_{2}$ adsorbed distances based on this test is between 1.95 and $2.15 \AA$, which aligns well with chemical reasoning based on the estimated adsorption enthalpy.

A final refinement constraining the $\mathrm{D}_{2}$ location to be at the location of the minimum distance vs $R_{\text {wp }}$ was performed, which refined to a $\mathrm{V}-\mathrm{D}_{2}$ superatom distance of $1.966(8)$. $\mathrm{D}_{2}$ occupancy was 
refined and $U_{\text {iso }}$ (indicative of the degree of quantum rotation, zero-point energy, and vibrations against the $\mathrm{V}$ ) was fixed to a chemically reasonable value.

Electronic structure calculations. A cluster model was constructed with two vanadium centers for quantum chemical modeling of the $\mathrm{H}_{2}$ binding to $\mathrm{V}_{2} \mathrm{Cl}_{2.8}$ (btdd). Since the framework comprises an admixture of $60 \%$ vanadium(II) and $40 \%$ vanadium(III) sites, our model features two adjacent vanadium centers of +2 and +3 charge. To be consistent with neutron diffraction measurements of the binding site, the vanadium(III) site was capped with a chloride ion, and the vanadium(II) site was bound to a hydrogen molecule. Vanadium centers were surrounded by 2 apical triazole moieties, 2 bridging triazolates, 1 bridging chloride, and 3 apical chloride ions. Both apical and one of the two bridging triazolate rings were protonated for charge balance. Spin multiplicity $(2 S+1)$ of the cluster due to unpaired electrons at two vanadium centers was 6 .

Using a guess geometry provided by solid state structure of the framework, geometry was optimized with the $\omega \mathrm{B} 97 \mathrm{~m}-\mathrm{v}$ functional in crenbl basis, with an effective core potential of fitcrenbl. Optimal coordinates for the hydrogen loaded framework were obtained by relaxing all nuclear degrees of freedom in the framework. Overall, the cluster is a faithful representation with some notable differences. The dihedral angle of the two ligating equatorial triazoles is $25.6^{\circ}$ in the relaxed structure while it is $74(4)^{\circ}$ in the experimental structure. The distortion from planarity of the weakly $\pi$-acidic triazoles likely attenuates the vanadium-ligand $\pi$ interactions. This notable difference is explained by the constraints imposed by the extended connectivity of the experimental structure. This is an example of how local metal coordination in frameworks can differ greatly from what may be anticipated in a molecular system.

An energy decomposition analysis was performed on the cluster with a loaded hydrogen molecule to systematically delineate interactions. For the vanadium(II) center, energy lowering due to polarization was found to contribute a small fraction of the total binding energy. The charge transfer term was significant, and its further decomposition into forward and back-bonding components showed a major contribution from forward donation. 

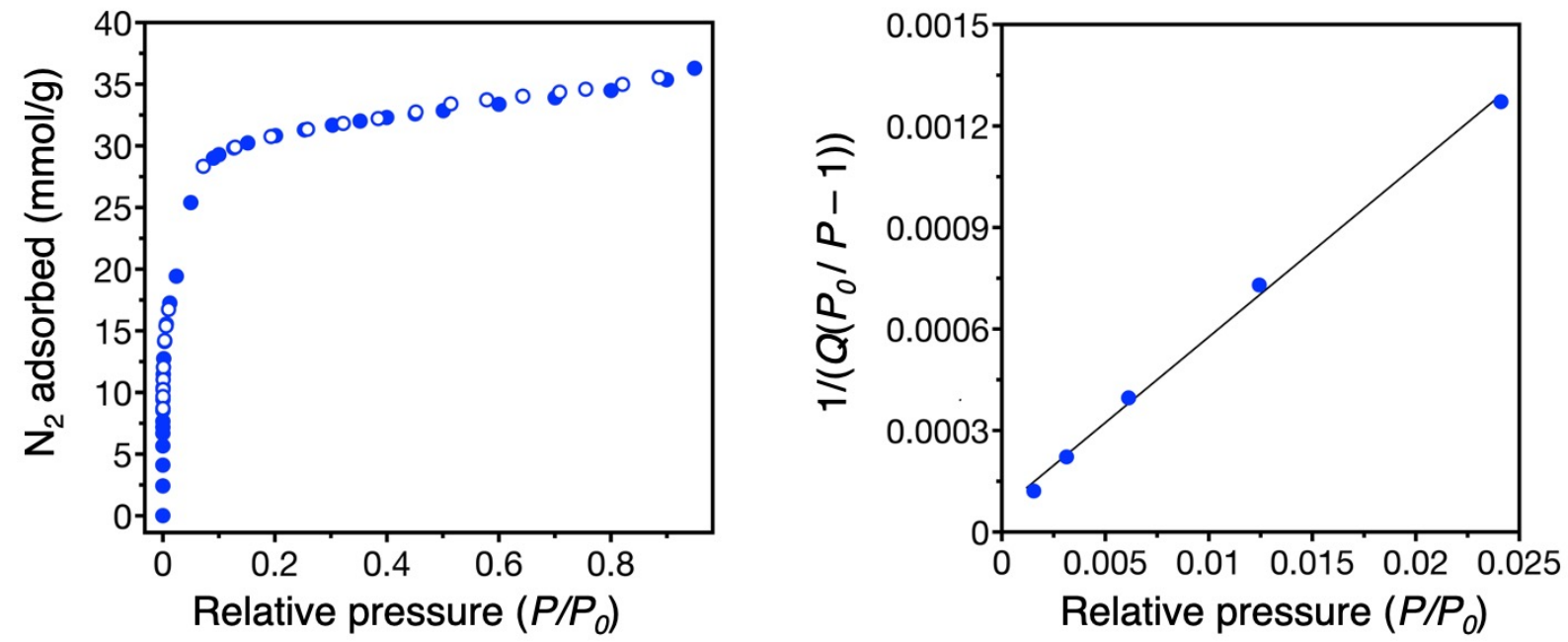

Figure S1. $77 \mathrm{~K} \mathrm{~N}_{2}$ isotherm (left) with desorption points shown as open circles. The Langmuir surface area is $3350 \pm 15 \mathrm{~m}^{2} / \mathrm{g}$. On the right is the BET plot. The BET surface area is $1920 \pm 60$ $\mathrm{m}^{2} / \mathrm{g}$. The BET parameters are shown in Table S1.

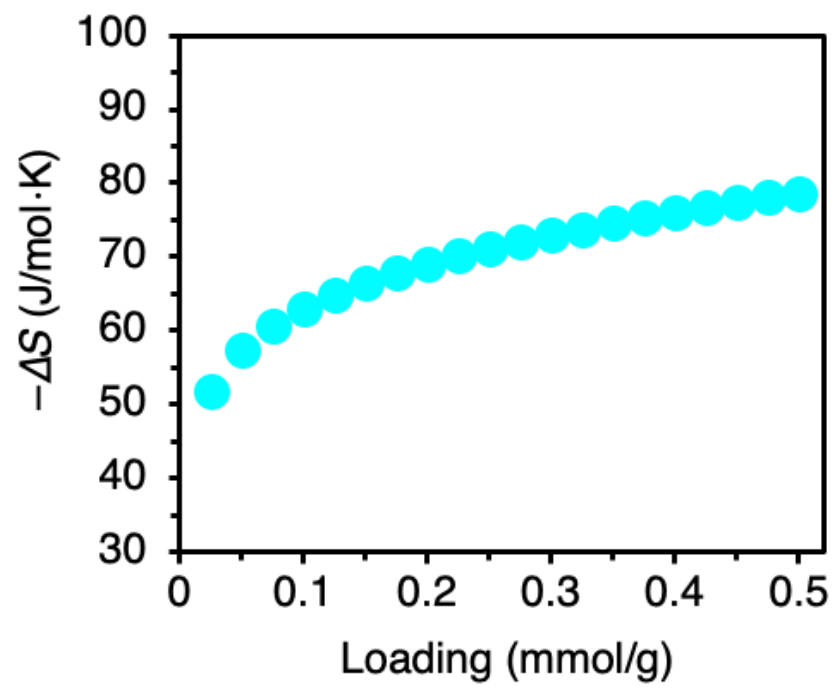

Figure S2. Entropy of $\mathrm{H}_{2}$ adsorption in $\mathrm{V}_{2} \mathrm{Cl}_{2.8}$ (btdd) as a function of loading, which was calculated by determining the $y$-intercept from eq. 3 . The average value across this loading is $69.9 \pm 0.6$ $\mathrm{J} /(\mathrm{mol} \cdot \mathrm{K})$. 


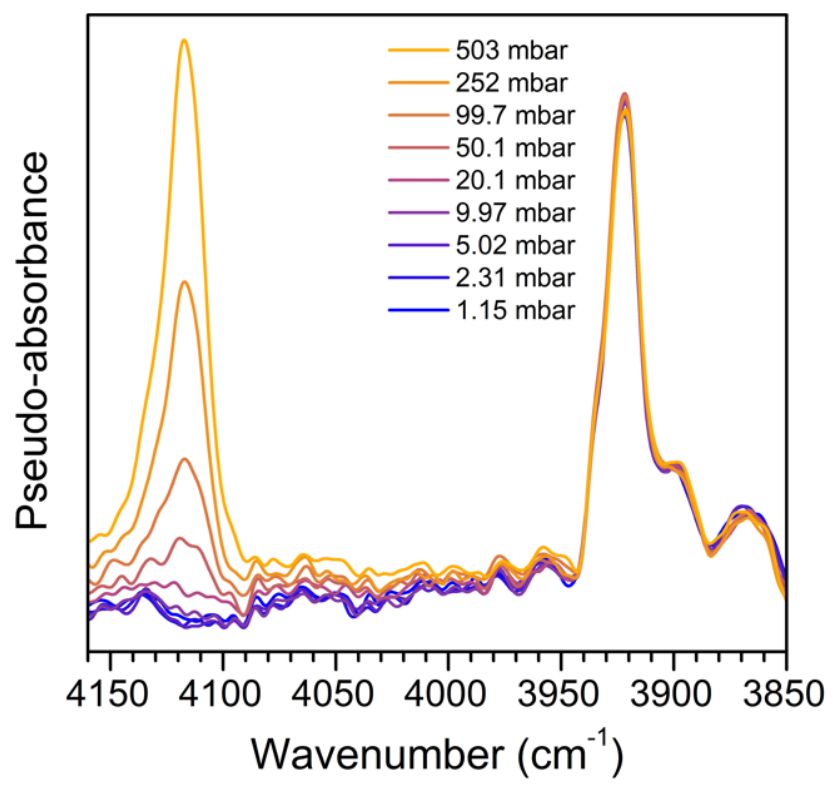

Figure S3. Difference infrared spectra of $\mathrm{V}_{2} \mathrm{Cl}_{2.8}$ (btdd) dosed under various pressures of $\mathrm{H}_{2}$ at 120 $\mathrm{K}$, with the empty framework as background. The feature at $3919 \mathrm{~cm}^{-1}$ saturates almost immediately while the feature at $4120 \mathrm{~cm}^{-1}$ gradually appears. 


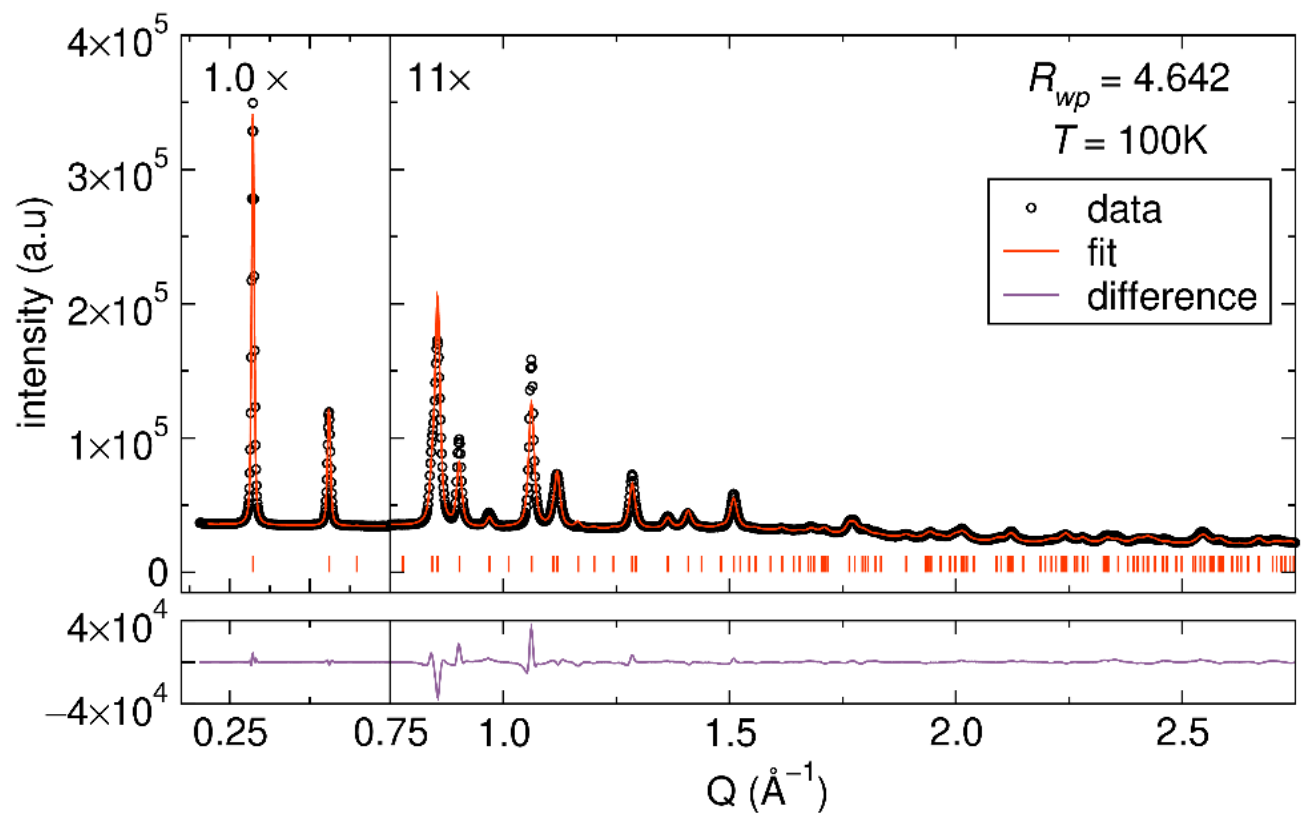

Figure S4. Rietveld refinement of powder X-ray diffraction data of for activated $\mathrm{V}_{2} \mathrm{Cl}_{2.8}$ (btdd) [APS, 17-BM, $\lambda=0.45246 \AA$ ] $, R \overline{3} m, a=38.8820(9) \AA, c=8.310(1) \AA ̊ \quad V=10880(3) \AA^{3}$. Goodnessof-fit parameters: $R_{w p}=4.64 \% ; R_{p}=3.12 \%$. Values in parentheses indicate one standard deviation.

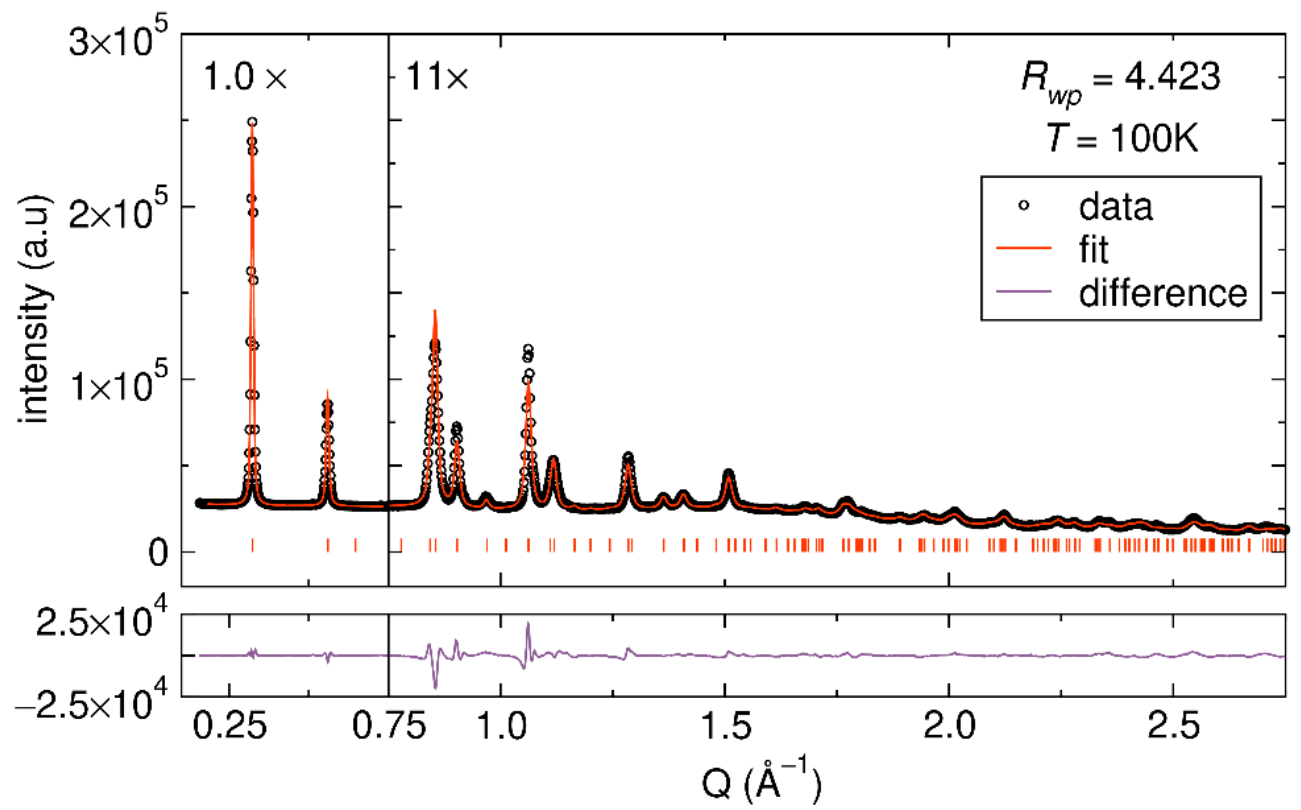

Figure S5. Rietveld refinement of powder $\mathrm{X}$-ray diffraction data for $\mathrm{D}_{2}$-dosed $\mathrm{V}_{2} \mathrm{Cl}_{2.8}$ (btdd) [APS, 17-BM, $\lambda=0.45246 \AA]$ ], $R \overline{3} m, a=38.903(3) \AA, c=8.303(1) \AA V=10882(2) \AA^{3}$. Goodness-of-fit parameters: $R_{w p}=4.42 \% ; R_{p}=2.93 \%$. Values in parentheses indicate one standard deviation. 


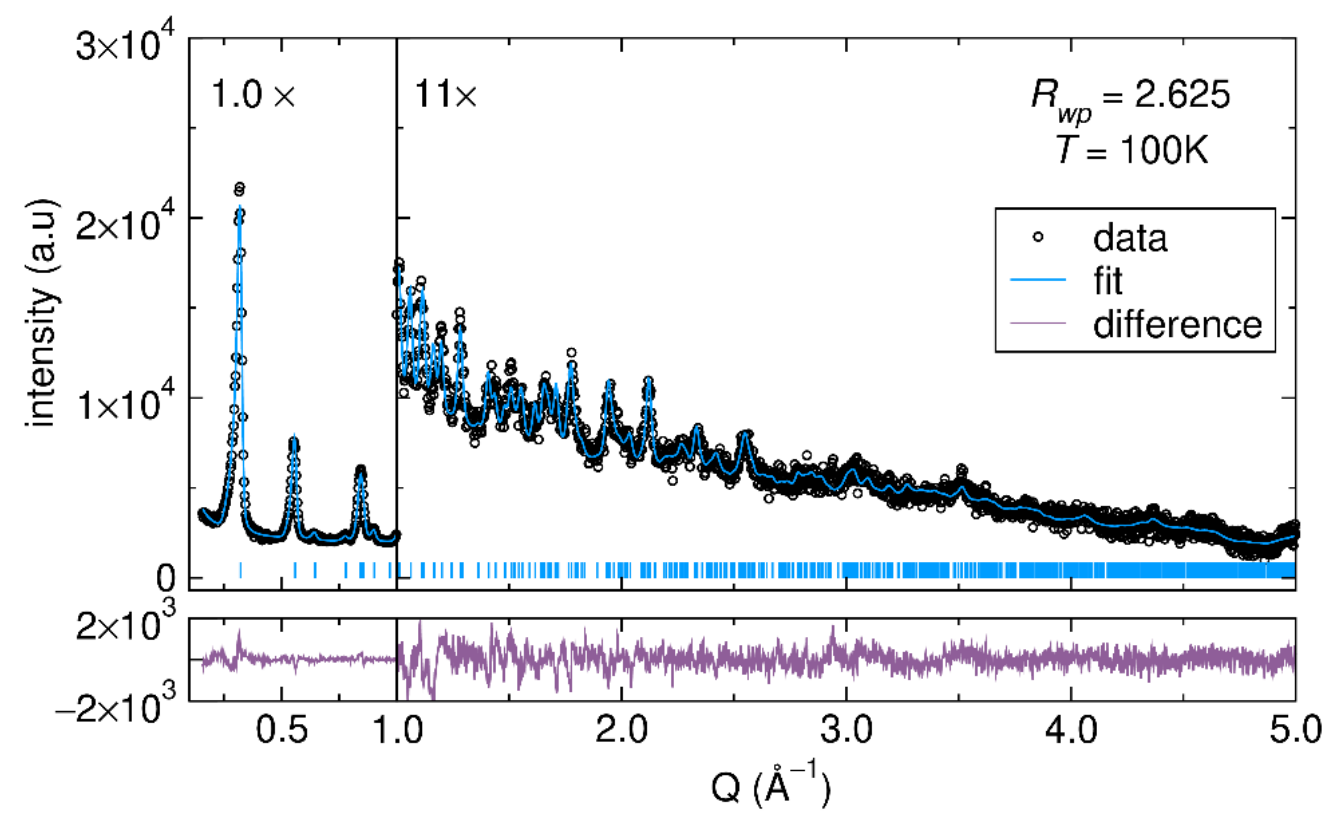

Figure S6. Rietveld refinement of powder neutron diffraction data for activated $\mathrm{V}_{2} \mathrm{Cl}_{2.8}$ (btdd) [NCNR, BT- $1, \lambda=2.079 \AA$ ] $, R \overline{3} m, a=38.8820(9) \AA, c=8.310(1) \AA V=10880(3) \AA^{3}$. Goodnessof-fit parameters: $R_{w p}=2.63 \% ; R_{p}=2.32 \%$. Values in parentheses indicate one standard deviation.

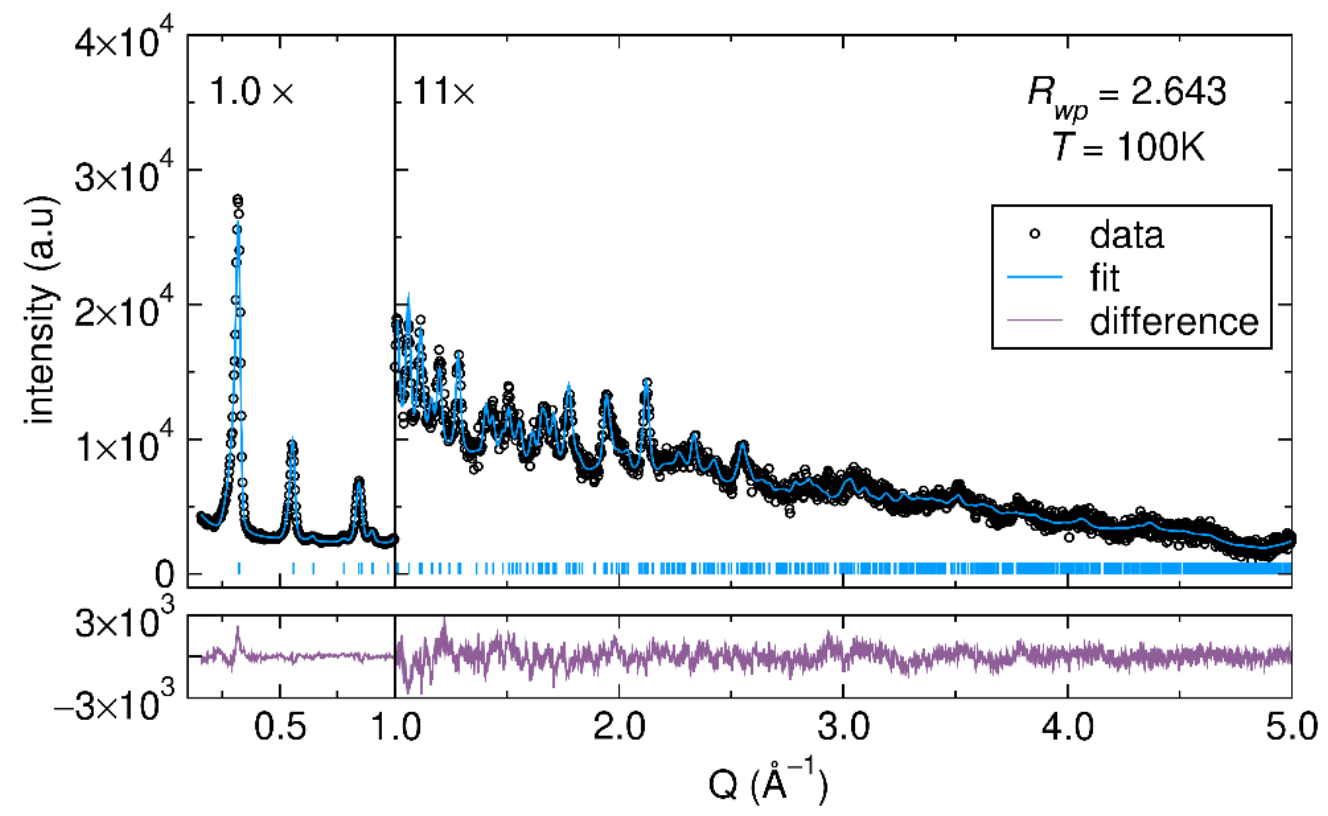

Figure S7. Rietveld refinement of powder neutron diffraction data for $0.75 \mathrm{D}_{2}$ per V(II), $\mathrm{V}_{2} \mathrm{Cl}_{2.8}$ (btdd) [NCNR, BT-1, $\lambda=2.079 \AA$ ] $, R \overline{3} m, a=38.903(3) \AA, c=8.303(1) \AA V=10882(2) \AA^{3}$. Goodness-of-fit parameters: $R_{w p}=2.64 \% ; R_{p}=2.42 \%$. Values in parentheses indicate one standard deviation. 


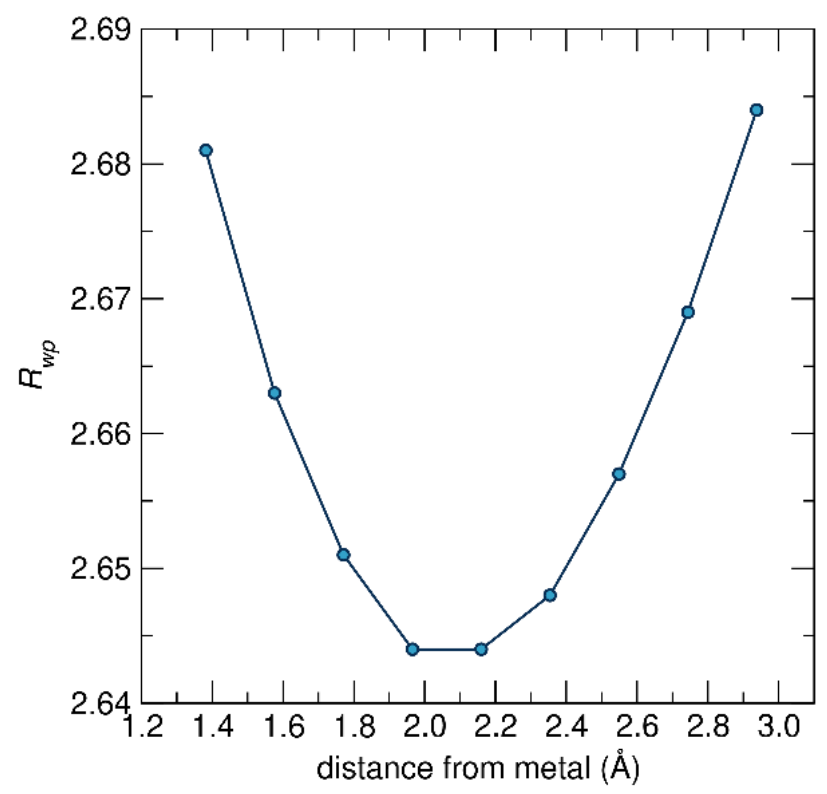

Figure S8. $R_{w p}$ versus D superatom position for $0.75 \mathrm{D}_{2}$ dosed $\mathrm{V}_{2} \mathrm{Cl}_{2.8}$ (btdd) from neutron diffraction Rietveld refinement. The super atom position was varied along the special position of $x, 0,0.5$, while holding everything else constant, in order to estimate the possible statistical equivalence of $\mathrm{D}_{2}$ positions.

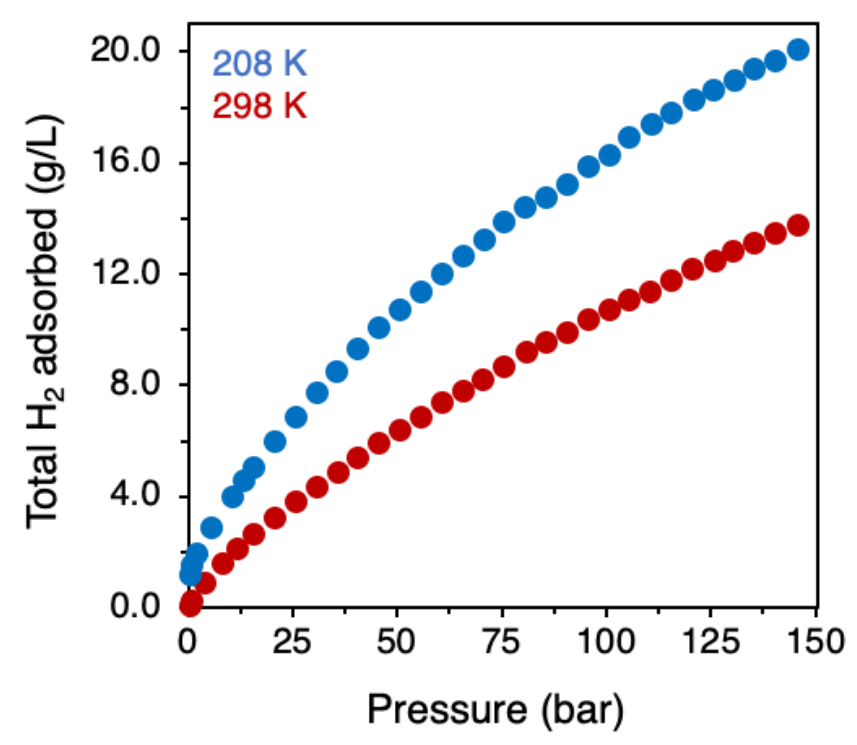

Figure S9. High-pressure total uptake hydrogen isotherms of $\mathrm{V}_{2} \mathrm{Cl}_{2.8}($ btdd). Blue and red circles denote collection at $208 \mathrm{~K}$ and $298 \mathrm{~K}$ respectively. 


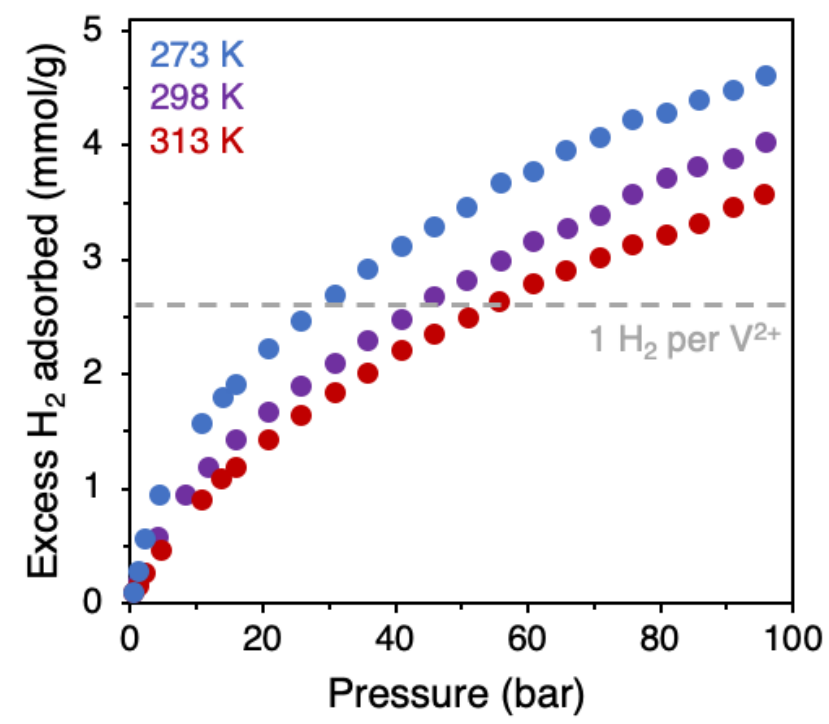

Figure S10. High-pressure excess uptake hydrogen isotherms in $\mathrm{V}_{2} \mathrm{Cl}_{2.8}($ btdd). Blue, purple, and red circles denote collection at 273,298, and $318 \mathrm{~K}$, respectively. The grey dotted line corresponds to the capacity of one $\mathrm{H}_{2}$ molecule bound per open vanadium(II) site.

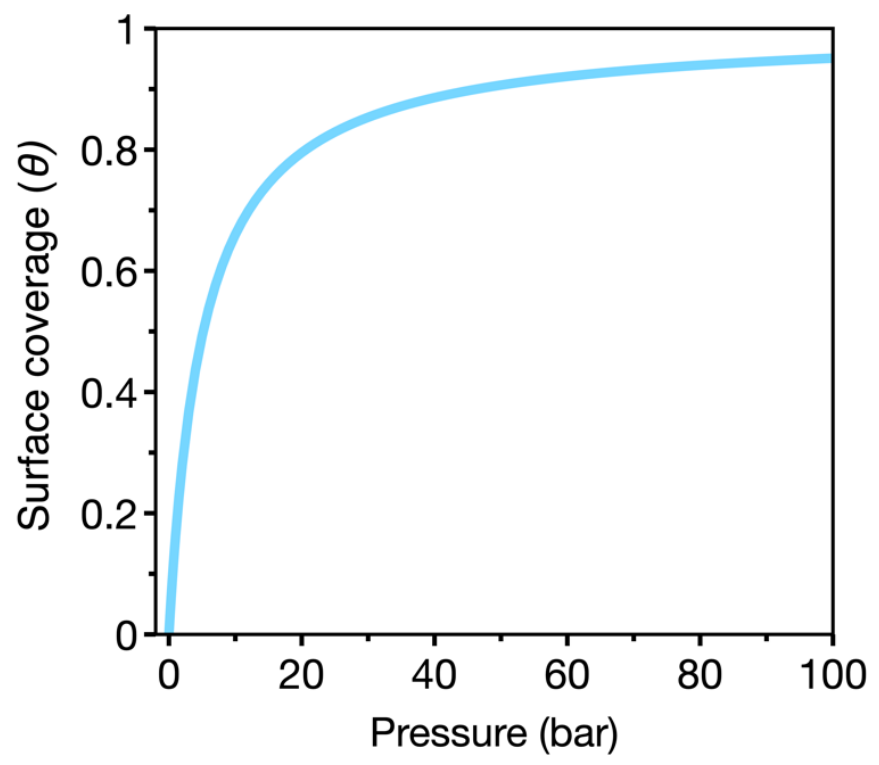

Figure S11. Calculated single-site $298 \mathrm{~K}$ hydrogen isotherm using free energy parameters obtained experimentally $(\Delta H=-21.0 \mathrm{~kJ} / \mathrm{mol}, \Delta S=-84.1 \mathrm{~J} / \mathrm{mol} \cdot \mathrm{K})$. Surface coverage $(\theta)$ is equal to $n / n_{\text {sat }} .90 \%$ of vanadium site saturation is reached at 50 bar. 


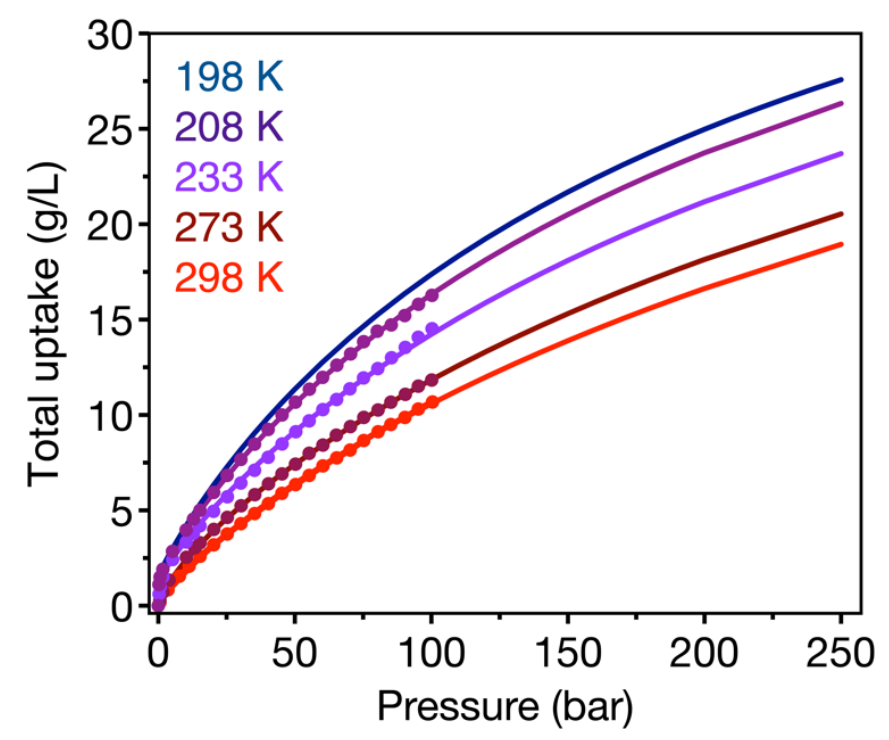

Figure S12. Experimental high-pressure $\mathrm{H}_{2}$ uptake (circles) and isotherm fits (lines) calculated using a dual-site Langmuir-Freundlich model (see Table S3 for fit parameters).

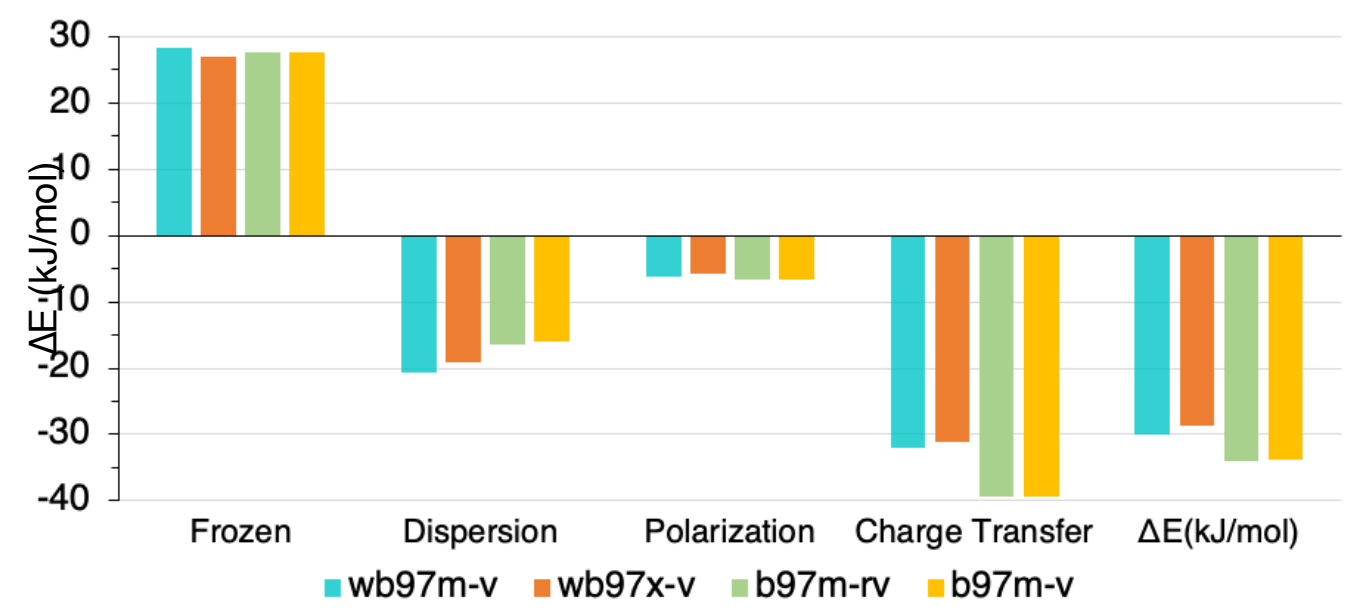

Figure S13. EDA analysis for $\mathrm{H}_{2}$ binding to the cluster for some top performing functionals. 
$\mathrm{H}_{2}$ HOMO to $\mathrm{V}^{\prime \prime}$

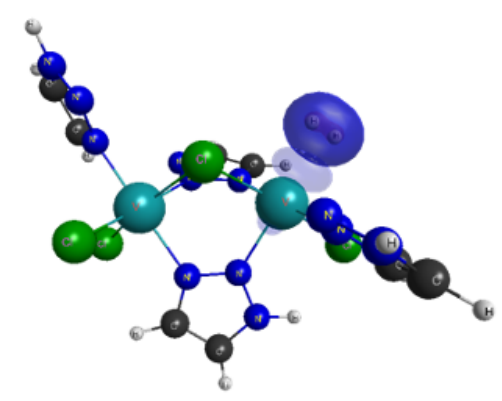

V" to $\mathrm{H}_{2}$ LUMO

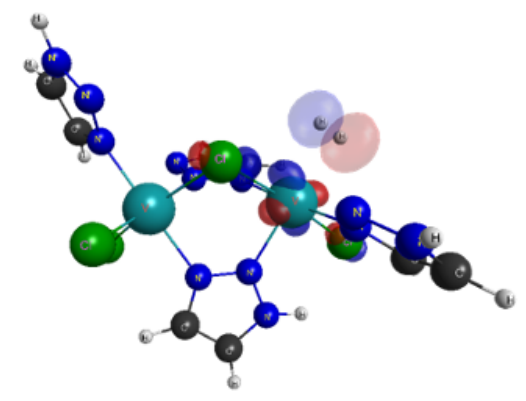

Figure S14. Calculated charge transfer orbital pairs in the cluster model, showing the $\mathrm{H}_{2} \sigma$ (HOMO) to $\mathrm{V}^{\mathrm{II}}$ interaction (left) and the $\mathrm{V}^{\mathrm{II}} d_{\pi}$ to $\mathrm{H}_{2} \sigma^{*}$ (LUMO) interaction (right). 
Table S1. BET parameters for the $77 \mathrm{~K}$ adsorption $\mathrm{N}_{2}$ isotherm (Fig. S1). $Q_{m}$ is the monolayer capacity.

\begin{tabular}{lc}
\hline Parameter & Values \\
\hline BET area $\left(\mathrm{m}^{2} / \mathrm{g}\right)$ & $1920 \pm 60$ \\
Pressure region $\left(P / P_{0}\right)$ & $0.0015-0.024$ \\
Correlation coefficient & 0.999 \\
$C$ & 739 \\
$Q_{\mathrm{m}}(\mathrm{mmol} / \mathrm{g})$ & 19.7 \\
$1 /\left(C^{1 / 2}+1\right)$ & 0.035 \\
\hline
\end{tabular}

Table S2. Fitting parameters to the tri-site Langmuir-Freundlich equation (eq. 1 and 2) for lowpressure $\mathrm{H}_{2}$ adsorption at 273,286 , and $298 \mathrm{~K}$.

\begin{tabular}{lccc}
\hline Parameter & \multicolumn{3}{c}{ Values } \\
\hline & Site 1 & Site 2 & Site 3 \\
$n_{\text {sat }, 1}(\mathrm{mmol} / \mathrm{g})$ & 0.89 & 0.85 & 4.71 \\
$E_{1}(-\mathrm{kJ} / \mathrm{mol})$ & 23.6 & 19.4 & 7.10 \\
$S_{1}(-\mathrm{J} / \mathrm{mol} \cdot \mathrm{K})$ & 97.1 & 79.5 & 106.3 \\
$v_{1}$ & 0.97 & 1.06 & 0.91 \\
\hline
\end{tabular}

Table S3. Fitting parameters to the dual-site Langmuir-Freundlich equation (eq. 1 and 2) for high-pressure $\mathrm{H}_{2}$ adsorption at 208, 233, 273, 298, and $313 \mathrm{~K}$.

\begin{tabular}{l|cc}
\hline Parameter & \multicolumn{2}{|c}{ Values } \\
\hline & Site 1 & Site 2 \\
$n_{\text {sat }, 1}(\mathrm{mmol} / \mathrm{g})$ & 1.18 & 39.3 \\
$E_{1}(-\mathrm{kJ} / \mathrm{mol})$ & 35.0 & 3.35 \\
$S_{1}(-\mathrm{J} / \mathrm{mol} \cdot \mathrm{K})$ & 143.7 & 58.7 \\
$v_{1}$ & 1 & 0.92 \\
\hline
\end{tabular}


Table S4. Zero-point energy (ZPE) calculations and temperature effects at $298 \mathrm{~K}$ and 1 atm computed at b3lyp-d2 level of theory for the fully relaxed cluster model.

\begin{tabular}{cccccc}
$\begin{array}{c}\Delta \mathrm{PE} \\
(\mathrm{kJ} / \mathrm{mol})\end{array}$ & $\begin{array}{c}\Delta U_{\text {vib }} \\
(\mathrm{kJ} / \mathrm{mol})\end{array}$ & $\begin{array}{c}\Delta E \\
(\mathrm{~kJ} / \mathrm{mol})\end{array}$ & $\begin{array}{c}\Delta H \\
(\mathrm{~kJ} / \mathrm{mol})\end{array}$ & $\begin{array}{c}\Delta S \\
(\mathrm{~J} / \mathrm{mol} \cdot \mathrm{K})\end{array}$ & $\begin{array}{c}\Delta G \\
(\mathrm{~kJ} / \mathrm{mol})\end{array}$ \\
\hline 12.08 & 10.13 & -30.06 & -19.93 & -87.81 & 6.25 \\
\hline
\end{tabular}

Table S5. EDA of cluster models in which only the $\mathrm{H}_{2}$ molecule is allowed to relax $\left(\mathrm{H}_{2}\right.$ relaxed) or where only $\mathrm{H}_{2}$ and vanadium atom are allowed to relax $\left(\mathrm{V}-\mathrm{H}_{2}\right.$ relaxed). All other nuclear coordinates are fixed to the experimental values.

\begin{tabular}{lcc}
\hline \multicolumn{1}{c|}{ Component } & \multicolumn{2}{c}{ Energy $(\mathrm{kJ} / \mathrm{mol})$} \\
\hline & $\mathbf{H}_{2}$ relaxed & $\begin{array}{c}\mathbf{V}-\mathbf{H}_{2} \\
\text { relaxed }\end{array}$ \\
Frozen & 7.53 & 7.22 \\
Polarization & -5.65 & -5.81 \\
Charge transfer & -29.78 & -30.35 \\
Total & -27.61 & -27.26 \\
\hline
\end{tabular}




\section{References}

(1) Jaramillo, D. E.; Reed, D. A.; Jiang, H. Z. H.; Oktawiec, J.; Mara, M. W.; Forse, A. C.; Lussier, D. J.; Murphy, R. A.; Cunningham, M.; Colombo, V.; Shuh, D. K.; Reimer, J. A.; Long, J. R. Selective Nitrogen Adsorption via Backbonding in a Metal-Organic Framework with Exposed Vanadium Sites. Nat. Mater. 2020, 19, 517-521.

(2) Kapelewski, M. T.; Runčevski, T.; Tarver, J. D.; Jiang, H. Z. H.; Hurst, K. E.; Parilla, P. A.; Ayala, A.; Gennett, T.; Fitzgerald, S. A.; Brown, C. M.; Long, J. R. Record High Hydrogen Storage Capacity in the Metal-Organic Framework $\mathrm{Ni}_{2}(m$-dobdc) at NearAmbient Temperatures. Chem. Mater. 2018, 30, 8179-8189.

(3) Pawley, G. S. Unit-Cell Refinement from Powder Diffraction Scans. J. Appl. Crystallogr. 1981, 14, 357-361.

(4) Pollock, R. A.; Her, J. H.; Brown, C. M.; Liu, Y.; Dailly, A. Kinetic Trapping of $\mathrm{D}_{2}$ in MIL53(Al) Observed Using Neutron Scattering. J. Phys. Chem. C 2014, 118, 18197-18206.

(5) Brown, C. M.; Liu, Y.; Yildirim, T.; Peterson, V. K.; Kepert, C. J. Hydrogen Adsorption in HKUST-1: A Combined Inelastic Neutron Scattering and First-Principles Study. Nanotechnology 2009, 20, 204025.

(6) Wu, H.; Zhou, W.; Yildirim, T. Hydrogen Storage in a Prototypical Zeolitic Imidazolate Framework-8. J. Am. Chem. Soc. 2007, 129, 5314-5315.

(7) Gonzalez, M. I.; Kapelewski, M. T.; Bloch, E. D.; Milner, P. J.; Reed, D. A.; Hudson, M. R.; Mason, J. A.; Barin, G.; Brown, C. M.; Long, J. R. Separation of Xylene Isomers through Multiple Metal Site Interactions in Metal-Organic Frameworks. J. Am. Chem. Soc. 2018, $140,3412-3422$. 